\title{
Nota \\ CONTROLE DE Cerconota anonella EM POMAR DE GRAVIOLEIRA
}

\author{
Sônia Maria Forti Broglio-Micheletti ${ }^{1}$; Evôneo Berti-Filho* \\ ${ }^{1}$ Depto. de Fitotecnia e Fitossanidade, Campus Delza Gitaí - CECA/UFAL, BR 104, Km 85 - CEP: 57100-000 - \\ Rio Largo, AL. \\ ${ }^{2}$ Depto. de Entomologia, Fitopatologia e Zoologia Agricola - ESALQ/USP, C.P. 9 - CEP: 13418-900 - Piracicaba, SP. \\ ${ }^{*}$ Autor correspondente <eberti@carpa.ciagri.usp.br>
}

RESUMO: Testaram-se métodos químico e cultural para o controle de Cerconota anonella (Sepp., 1830) (Lepidoptera: Oecophoridae), principal praga da gravioleira (Annona muricata L.). O delineamento experimental utilizado foi o inteiramente casualizado, com 9 tratamentos e 20 repetições. Os melhores resultados foram obtidos com saco plástico microperfurado e papel kraft tratado com clorpirifós.

Palavras-chave: Insecta, broca-dos-frutos, graviola

\section{CONTROL OF Cerconota anonella IN A SOURSOP ORCHARD}

\begin{abstract}
This research is related to the control of Cerconota anonella (Sepp.) (Lepidoptera: Oecophoridae), the most important pest of soursop, Annona muricata L. Nine treatments were tested with twenty replications in a completely randomized design. The best results were obtained using microperforated plastic bags and clorphiriphos treated kraft paper bags.

Key words: Insecta, soursop fruit borer, soursop
\end{abstract}

\section{INTRODUÇÃO}

A graviola é uma fruta tropical de grande aceitação comercial, sendo amplamente cultivada nas regiões Norte, Nordeste, Centro-Oeste e Sudeste (Junqueira et al. 1996). Entretanto, a broca-do-fruto, Cerconota anonella (Sepp.) (Lepidoptera: Oecophoridae) limita o cultivo dessa planta, pelos danos expressivos que causa ao fruto, reduzindo a produção da cultura.

Os adultos são mariposas de coloração brancoacinzentada com reflexos prateados. As posturas são feitas aleatoriamente no fruto e em diferentes estágios de desenvolvimento, embora preferencialmente naqueles verdes. O dano é causado pelas larvas, que formam galerias na polpa por onde penetram patógenos e outros insetos, deixando o fruto impróprio para a comercialização. $O$ ciclo de vida de $C$. anonella, de ovo a adulto, foi de 36,4 dias (Bustillo e Peña, 1992). As perdas causados por esta praga podem variar de 70 a $100 \%$ da produção (Ruiz, 1991)

Algumas medidas de controle culturais são indicadas para $C$. anonella, tais como catação e queima ou enterrio dos frutos atacados, poda de formação e rejuvenescimento e também medidas físicas como a utilização de armadilhas luminosas (Melo et al.1983, Calzavara \& Müller 1987, EMATER, 1989).

Diferentes tipos de invólucros foram utilizados na proteção de frutos de graviola, para o controle de $C$. anonella. (Doesburg 1964, Melo et al. 1983, McComie 1987, Carneiro \& Bezerril 1993, Manica 1994). Bustillo \& Peña (1992) utilizaram invólucros juntamente com inseticidas e o melhor resultado foi a utilização de clorpirifós
+ saco plástico, que apresentou $92 \%$ dos frutos sádios.

Este estudo teve por objetivo avaliar o controle de C. anonella em frutos de graviola, utilizando-se dos métodos de controle químico e cultural.

\section{MATERIAL E MÉTODOS}

Os experimentos foram conduzidos em pomar de graviola, em Maceió, AL, no período de 29/04/1997 a 22/ 09/1997. Utilizaram-se vinte frutos, com 1 a $3 \mathrm{~cm}$ de comprimento. Estes foram selecionados e marcados com fio de nylon colorido e etiquetados para identificar cada tratamento.

Os tratamentos utilizados foram: 1- frutos sem proteção (testemunha), 2- fruto sadio engaiolado (gaiola de armação de arame, revestida com filó), 3- fruto coberto com saco de papel kraft, 4- tratamento externo do saco de papel kraft com clorpirifós $480 \mathrm{~g} \mathrm{~L}^{-1}$, na dose de 300 $\mathrm{mL} 100 \mathrm{~L}^{-1}$ de água e ensacamento, 5 - fruto ensacado com saco plástico, perfurado na extremidade inferior, 6- fruto ensacado com saco plástico microperfurado, 7- fruto ensacado com saco de papel impermeável nas duas faces, 8- pulverização dos frutos semanal e localizada, com triflumuron (PM) $250 \mathrm{~g} \mathrm{~kg}^{-1}$, sendo a dose $100 \mathrm{~g} \mathrm{ha}^{-1}$, 9pulverização com triflumuron (PM) $250 \mathrm{~g} \mathrm{~kg}^{-1}$, na dose 100 $\mathrm{g} \mathrm{ha}^{-1}$, sendo posteriormente os frutos ensacados com saco plástico microperfurado.

Os sacos foram presos aos ramos acima dos frutos, por meio de arame plastificado. Semanalmente, até a colheita, foram realizadas inspeções para a verificação de queda de frutos e/ou danificação do invólucro. 
A eficiência dos tratamentos foi medida através da contagem do número de orifícios feitos nos frutos por C. anonella, nos diferentes tratamentos. Foram avaliados também, o peso total de fruto colhido, número de frutos caídos, número de frutos colhidos com e sem dano, peso, comprimento e maior diâmetro médios e preços para os diferentes materiais usados para o ensacamento e para o controle químico. Foram usadas como indicativos do ponto de colheita as características descritas por Pinto \& Silva (1994), ou seja, mudança na coloração da casca (verde escura para verde clara), quebra das espículas com facilidade e polpa relativamente mole ao ser o fruto levemente pressionado com os dedos. Os dados foram submetidos à análise de variância e as diferenças entre as médias tratadas pelo teste de Tukey a $5 \%$.

\section{RESULTADOS E DISCUSSÃO}

Em relação aos resultados do número médio de orifícios/fruto (TABELA 1), os tratamentos (3 a 9): triflumuron, gaiola, triflumuron + saco plástico microperfurado, papel kraft + clorpirifós, papel kraft, papel impermeável e saco plástico microperfurado diferiram estatisticamente da testemunha e do tratamento com saco plástico, enquanto que estes dois últimos tratamentos não diferiram.

TABELA 1 - Número médio de orifícios em frutos de graviola ( \pm EP) ocasionados por Cerconota anonella nos diferentes tratamentos, número total de frutos colhidos e porcentagem de frutos colhidos sem dano. Sítio Aldeia Verde, Maceió/AL, 29/04/1997 - 22/09/1997.

\begin{tabular}{cccc}
\hline Tratamento & $\begin{array}{c}\mathrm{N}^{\circ} \text { médio de } \\
\text { orifícios/fruto } \\
\pm E P\end{array}$ & $\begin{array}{c}\mathrm{N}^{\circ} \text { total de } \\
\text { frutos } \\
\text { colhidos e } \\
\text { avaliados }\end{array}$ & $\begin{array}{c}\% \text { de fruto } \\
\text { collhido } \\
\text { sem dano }\end{array}$ \\
\hline 1 & $1,68 \pm 0,174 \mathrm{a}$ & 10 & 10,0 \\
\hline 2 & $1,17 \pm 0,233 \mathrm{ab}$ & 8 & 62,5 \\
\hline 3 & $1,00 \pm 0,127 \mathrm{~b}$ & 15 & 66,7 \\
\hline 4 & $0,92 \pm 0,109 \mathrm{~b}$ & 11 & 72,7 \\
\hline 5 & $0,85 \pm 0,102 \mathrm{~b}$ & 12 & 83,3 \\
\hline 6 & $0,78 \pm 0,067 \mathrm{~b}$ & 13 & 92,3 \\
\hline 7 & $0,77 \pm 0,064 \mathrm{~b}$ & 8 & 87,5 \\
\hline 8 & $0,77 \pm 0,064 \mathrm{~b}$ & 8 & 87,5 \\
\hline 9 & $0,75 \pm 0,043 \mathrm{~b}$ & 12 & 91,7 \\
\hline
\end{tabular}

$\mathrm{CV}=40,45 \%$

As médias seguidas por letras distintas diferem pelo teste de Tukey a $5 \%$.

Os valores foram transformados em $\sqrt{x+0,5}$

('): 1- testemunha, 2- saco plástico, 3- triflumuron $250 \mathrm{~g} \mathrm{~kg}^{-1}, 100$ $\mathrm{g} \mathrm{ha}^{-1}$ 4- gaiola, 5- triflumuron $250 \mathrm{~g} \mathrm{~kg}^{-1}, 100 \mathrm{~g} \mathrm{ha}^{-1}+$ saco plástico microperfurado, 6- saco de papel kraft tratado externamente com clorpirifós $480 \mathrm{~g} \mathrm{~L}^{-1}, 300 \mathrm{~mL} 100 \mathrm{~L}^{-1}$ de água, 7- saco de papel kraft, 8- saco de papel impermeável dupla face, 9- saco plástico microperfurado.
Entre estes tratamentos, ou seja, de 3 a 9, se comparados pelas porcentagens de frutos colhidos sem dano observa-se, embora não significativamente, que os melhores resultados foram obtidos com saco plástico microperfurado e papel kraft tratado com clorpirifós, mas este tratamento teve uma média de frutos perfurados maior em relação ao tratamento com saco plástico microperfurado. Resultados semelhantes foram obtidos por Bustillo \& Peña (1992). O custo do tratamento com saco plástico microperfurado $(R \$ 0,035)$ foi maior do que 0 tratamento trifumuron, que também apresentou maior peso total de fruto colhido (TABELA 2). De acordo com Carneiro \& Bezerril (1993) a utilização de saco plástico + saco de papel (ambos $5 \mathrm{~kg}$ ), foi a mais indicada, por apresentar maior praticidade $\mathrm{e}$ economicidade. Entretanto, pelos resultados de orifícios médios/fruto, o tratamento trifumuron apresentou uma perfuração $25 \%$ maior do que o de sacos microperfurados.

Em relação aos pesos unitários dos frutos, comprimentos e maiores diâmetros médios, não houve diferença estatística entre os tratamentos.

Dessa forma, o tratamento com saco plástico microperfurado levou vantagem sobre os demais na maioria dos parâmetros analisados, o que permite inferir que se trata da melhor forma de controle testada para

TABELA 2 - Número de frutos comercializáveis, peso total de fruto colhido, porcentagem de frutos abortados e custos unitários das proteções de frutos por tratamento. Sítio Aldeia Verde, Maceió/ AL, 29/04/1997 - 22/09/1997.

\begin{tabular}{ccccc}
\hline Tratamento $^{1}$ & $\begin{array}{c}\text { No de }^{\circ} \text { drutos } \\
\text { comerci- } \\
\text { alizáveis }\end{array}$ & $\begin{array}{c}\text { Peso total } \\
\text { de fruto } \\
\text { colhido }\end{array}$ & $\begin{array}{c}\text { Perda } \\
\text { de } \\
\text { frutos }\end{array}$ & $\begin{array}{c}\text { Custo } \\
\text { unitário }\end{array}$ \\
\hline 1 & 10 & 7540,0 & 50 & - \\
\hline 2 & 8 & 10630,0 & 60 & 0,0130 \\
3 & 15 & 15150,0 & 25 & $0,0210^{3}$ \\
4 & 11 & 12390,0 & 45 & 7,4100 \\
5 & 12 & 13980,0 & 40 & 0,0560 \\
\hline 6 & 13 & 10140,0 & 35 & 0,0303 \\
7 & 8 & 8830,0 & 60 & 0,0270 \\
8 & 8 & 10340,0 & 60 & 0,2500 \\
9 & 12 & 13900,0 & 40 & 0,0350 \\
\hline
\end{tabular}

(1): 1 - testemunha, 2- saco plástico $(48,5 \mathrm{~cm} \times 28,0 \mathrm{~cm})$, 3- triflumuron $250 \mathrm{gkg}^{-1}, 100 \mathrm{~g} \mathrm{ha}^{-1} 4$ - gaiola ( $25 \mathrm{~cm}$ de diâmetro $\times 35 \mathrm{~cm}$ de altura), 5- triflumuron $250 \mathrm{~g} \mathrm{~kg}^{-1}, 100 \mathrm{~g} \mathrm{ha}^{-1}+$ saco plástico microperfurado $(39 \mathrm{~cm} \times 34 \mathrm{~cm}), 6$ - papel kraft $(42,5 \mathrm{~cm} \times 24,0 \mathrm{~cm})$ tratado com clorpirifós $480 \mathrm{~g} \mathrm{~L}^{-1}, 300 \mathrm{~mL} 100 \mathrm{~L}^{-1}$ de água, 7- papel kraft $(42,5 \mathrm{~cm}$ x24,0 cm), 8- papel impermeável dupla face $(45,0 \mathrm{~cm} \times 31,5 \mathrm{~cm}), 9$ saco plástico microperfurado $(39 \mathrm{~cm} \times 34 \mathrm{~cm})$.

${ }^{(2)}$ No custo unitário foi computado o valor dos invólucros e dos inseticidas.

(3) 12 aplicações. 
C. anonella que, além de proteger os frutos, traz a vantagem de não permitir o acúmulo de água nestas embalagens, já que, segundo McComie (1987), favoreceria o crescimento e a proliferação de microrganismos que causam podridão mole e/ou mumificação nos frutos.

O tamanho dos frutos selecionados para o início do ensacamento é um aspecto muito importante a ser considerado, pois ocorreram muitos abortamentos com as graviolas protegidas entre 1 e $3 \mathrm{~cm}$. Doesburg (1964) sugeriu que a proteção fosse feita em frutos que tivessem perdido as brácteas $(2,5 \mathrm{~cm}$ em comprimento). Para McComie (1987), melhor faixa ficaria entre 2,5 e $6,0 \mathrm{~cm}$ e Bustillo \& Peña (1992) iniciaram o controle quando os frutos tinham $4 \mathrm{~cm}$ em diâmetro. Portanto, nos ensaios desenvolvidos em campo, haveria que se considerar uma faixa de comprimento entre 3 a $6 \mathrm{~cm}$, que talvez fosse a ideal. Sugere-se também alterar o comprimento do invólucro para $0,50 \mathrm{~m}$, mantendo-se a mesma largura $(0,34 \mathrm{~m})$, pois alguns romperam-se devido ao desenvolvimento dos frutos.

O ensacamento é uma forma de controle viável e segura, mas a limpeza do campo deve ser o primeiro passo para se ter sucesso com controle de pragas em anonáceas, pois os adultos continuam a emergir de frutos infestados mesmo após eles terem caído ao solo, servindo como fonte de reinfestação. Na medida do possível, tais frutos devem ser removidos das árvores e do solo que fica sob elas e completamente destruídos.

\section{AGRADECIMENTOS}

Ao Engenheiro Agrônomo Ricardo Luiz R. Ramalho Cavalcanti pela gentileza em ceder a área para a realização do trabalho. À CAPES/PIDCT pelo auxílio financeiro. Aos funcionários do CECA/FIT/UFAL: Roseane Maria Lins e Silva e Eng ${ }^{\circ}$ Agrônomo Antonio Jorge de Araújo Viveiros, pela ajuda em campo.

\section{REFERÊNCIAS BIBLIOGRÁFICAS}

BUSTILLO, A.E.; PEÑA, J.E. Biology and control of the Annona fruit borer Cerconota anonella (Lepidoptera: Oecophoridae). Fruits, v.47, p.81-84, 1992.

CALZAVARA, B.B.G.; MÜLLER, C.H. Fruticultura tropical: a gravioleira Annona muricata L. Belém: EMBRAPA, CPATU, 1987. 36p. (Documento, 47).

CARNEIRO, J. da S.; BEZERRIL, E.F. Controle das brocas dos frutos (Cerconota anonella) e das sementes (Bephratelloides maculicolis) da graviola no planalto da Ibiapaba CE. Anais da Sociedade Entomológica do Brasil, v.22, p.155-160, 1993.

DOESBURG, P.H. van. Two insect pests of soursop in Surinam. Caribbean Agriculture, v.3, p.797-803, 1964.

EMPRESA DE ASSISTÊNCIA TÉCNICA E EXTENSÃO RURAL. Proposta para um manejo integrado de pragas e doenças da anonicultura. Maceió: EMATER/AL, 1989. $41 \mathrm{p}$.

JUNQUEIRA, N.T.V.; CUNHA, M.M. da; OLIVEIRA, M.A.S.; PINTO, A.C. de Q. Graviola para exportação: aspectos fitossanitários. Brasília: EMBRAPA, SPI, 1996. 67p. (Série Publicações Técnicas FRUPEX, 22).

MANICA, I. (Ed.) Fruticultura: cultivo das anonáceas ata, cherimólia e graviola. Porto Alegre: EVANGRAF, 1994. $117 p$.

McCOMIE, L.D. The soursop (Annona muricata L.) in Trinidad: its importance, pests and problems associated with pest control. Journal of the Agricultural Society of Trinidad and Tobago, n.87, p.42-55, 1987.

MELO, G.S. de; GONZAGA NETO, L.; MOURA, R.J.M. Cultivo da gravioleira (Annona muricata L.). Recife: IPA, 1983. 4p. (Instruções Técnicas , 13).

PINTO, A.C. de Q.; SILVA, E.M. da. Graviola para exportação: aspectos técnicos da produção. Brasília: EMBRAPA, SPI, 1994. 41p. (Série Publicações Técnicas FRUPEX, 7).

RUIZ, R.V. Manejo de problemas entomológicos en huertos de Guanabana. In: PLAGAS de frutales en Colombia y alternativas de manejo: Casos: Guanabana, Curuba, Citrico. Palmira: Universidad Nacional de Colombia, 1991. p.59-92.

Recebido em 20.01.99 